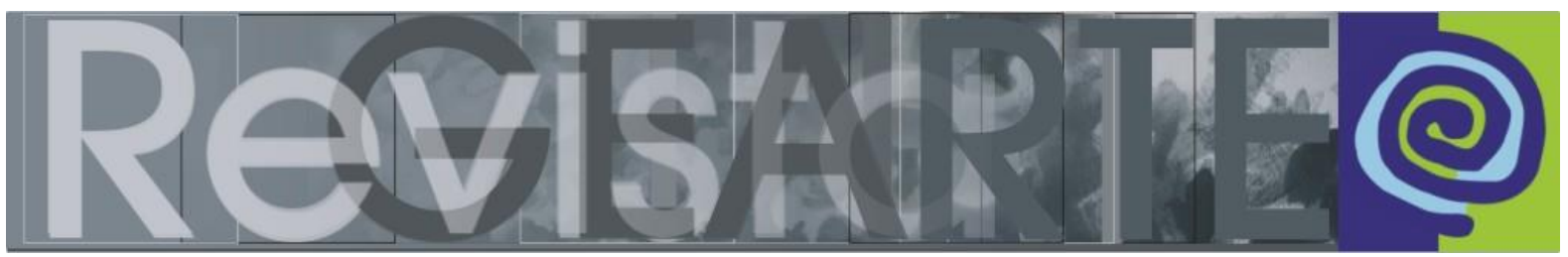

ISSN 2357-9854 | e-ISSN 2596-3198 (online)

\title{
Proposições educativas e formativas em arte: do (im)previsível dessas composições aos arranjos e invenções de uma aula
}

O Dossiê Proposições educativas e formativas em arte: do (im)previsível dessas composições aos arranjos e invenções de uma aula surgiu a partir de uma conversa que realizamos nos primeiros dias de 2021, um novo ano apesar de repleto das questões e dos problemas não resolvidos em 2020. A pandemia da COVID-19 nos forçou a tecer novas relações com o mundo e a nossa convivência com as tecnologias foi ao extremo entre lives, aulas online e outros tipos de atividades que buscavam uma comparação mimética com o real de outrora.

Na educação, as situações foram de um extremo ao outro, da exclusão ao seu acesso, tanto na educação básica quanto no ensino superior, até a extensa jornada de tempo em tela para docentes e estudantes. Em meio a esse cenário, nos indagamos sobre o nosso papel como docentes formadores de docentes e sobre as diferentes situações que vivenciamos no último período, do qual emergiu a pergunta sobre como começar uma aula. Não nos interessava a aula em si, mas a condição que aciona uma experiência de pensamento, que nos instiga a produzir um arranjo entre conceitos, práticas, imagens, objetos, referências que nos levam a compor uma aula.

Também não nos interessava identificar uma resposta unívoca para o questionamento que se apresentava, optamos em encontrar pessoas interessadas em conversar conosco a partir de uma rede de afetos que foi indicando lugares, instituições e pessoas que têm nos desafiado a pensar, diferentemente, as nossas práticas em educação e arte. Fomos desenhando um itinerário que levou em consideração as vozes e os saberes de colegas de diferentes lugares do nosso país e de outros também.

Assumimos um compromisso em alargar os espaços para dar visibilidade às mulheres, às pessoas LGBTQIA+, às pessoas negras e de outras culturas. Cada uma dessas pessoas foi recebendo nossas primeiras mensagens pelo e-mail e 


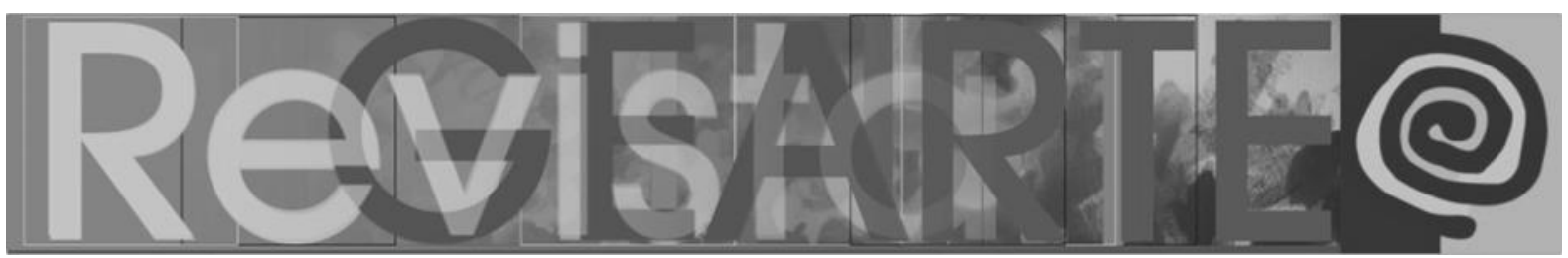

pelas redes sociais. Aos poucos, fomos preparando as condições para o envio de uma pergunta- convite ou de um convite-pergunta. Para acessar não somente a aula como o ato ou a coisa que ocorre no âmbito das instituições, pensamos no encontro e nos atos que ocorrem em escolas, universidades, oficinas, ateliês, museus e no próprio território.

O convite lançava as seguintes perguntas: como começar uma aula? De onde surgem as proposições educativas em arte? Ao fazê-las, interessava-nos pensar naquilo que nos aproxima: a docência, a arte, a educação; e que tantas vezes acaba sendo invisibilizado nas culturas universitárias, devido o estímulo ao produtivismo acadêmico. Ao perguntar sobre as composições e invenções que dão, ao nosso pensamento, as condições de exterioridade para que ele seja proposto às outras pessoas na forma-aula, sabíamos que não se tratava de uma questão simples e que para alguém até poderia ser uma interrogação sem lugar.

Ao desviar do mais comum - da coisa-aula, da coisa-curso e assemelhados e dos atos individuais de professoras/es - para dirigir a atenção ao imprevisível dessa composição antes do seu efetivo acontecimento, nos instigamos a pensar nas "[...] reviravoltas do saber" (FOUCAULT, 2020, p. 8) da arte e da educação para conversar com diferentes vozes sobre a maneira como temos (nos) experimentado na docência em arte. Pensar a partir de diferentes territórios, sejam eles geográficos, regionais, teóricos, artísticos, conceituais ou aqueles ainda não observados que vem do interesse pela partilha (RANCIĖRE, 2009) e pelos deslocamentos produzidos nos modos como temos acionado a arte e a educação na docência em arte.

Há uma dimensão política e de resistência importante neste dossiê quando, por exemplo, põe-se em convivência as experiências entre arte e natureza em um mestrado em Sevilha (Espanha) com a reivindicação de interação e convivência na experiência acadêmica (Brasil). Aproxima-se uma pesquisa sobre processos de criação e formação e uma residência artística em Nova Lima (Minas Gerais) que 


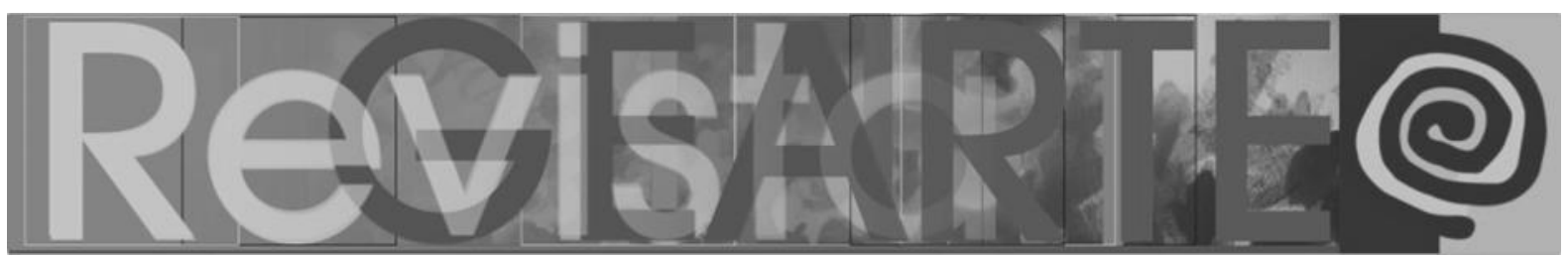

teve um desdobramento em uma escola. Avizinha-se a perspectiva docente em uma universidade em Macapá (AP), no Brasil, a um curso de pedagogia em Lleida, na Espanha.

A composição política do dossiê põe em proximidade o que se pensa desde os mundos da arte e da universidade, mas também desde um curso de pedagogia e as licenciaturas em artes visuais. De outra forma, ainda, esta disposição acolhe um mestrado em arte e cursos de graduação desde grandes capitais a cidades do interior e em pontos extremos do Brasil. Ainda que seja possível estabelecer aproximações territoriais e regionais, importa ressaltar que, nessa montagem, produziu- se um conjunto situado que sustenta uma zona comum de ação - ou uma comunidade docente - desde a arte.

Queremos resistir, contudo, ao que dessa reunião pode se tornar definitivo ou conclusivo para permitir proposições que podem ser inconcebíveis ou improváveis ${ }^{1}$ em um agrupamento circunscrito por arte e educação. Isso porque as ambiguidades, as complexidades e a implicação de cada abordagem com seu contexto não podem ser suprimidas ou diminuídas nas tensões que produzem.

Podemos dizer, então, que o agrupamento apresentado não é reconhecido por afinidade ou originalidade, mas pelas aberturas que introduzem, pelas conversações que ativam e pelos desvios que delineiam. Improvável e inconcebível, dessa maneira, não são demérito nem rejeição, mas uma maneira de abrir os códigos nos quais nos especializamos pesquisando.

No momento crítico do presente, quando se aventa não haver pós-pandemia porque pode ser que ela não regrida (IAMARINO, 2021), reunir uma comunidade em torno da docência, da arte, da aula, é uma tarefa política e de resistência, o que, de uma forma ou de outra, sempre existiu.

Em escolas, universidades ou instituições culturais, as proposições educativas em arte que se expressam na forma de aula, curso, oficina, residência 


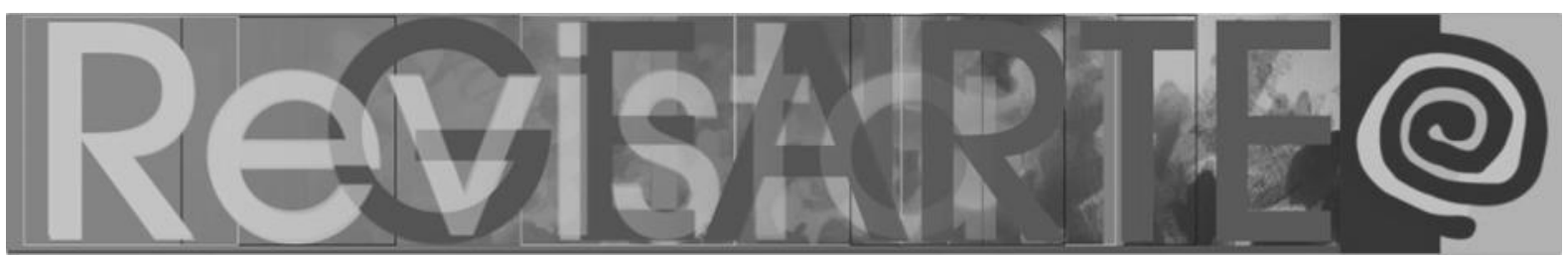

e afins se relacionam intimamente com contextos próprios e conhecidos, como os campos do saber de arte e educação, as atribuições institucionais e as culturas locais, mas que também se conectam a diversas zonas de pouca nitidez e previsibilidade (LADDAGA, 2012).

Tendo em vista essas zonas pouco tratadas, buscamos deslocar do ponto de vista metodológico, o mais visado e que se empenha em pensar como se ensina e aprende arte, para dar a ver e a pensar situações, estados e operações de uma composição exploratória e imprevisível. Ao fazer um outro recorte sobre o que tradicionalmente vem sendo analisado no exercício educativo em arte, esperamos trazer outros significados e direções sobre a docência no campo que transita entre educação e arte na escola, no ensino superior, em espaços de arte ou outros, indo a um ponto em que os vínculos entre educação e arte estão no domínio da possibilidade.

Essas questões ocorrem no momento em que a Lei de Diretrizes e Bases da Educação Nacional - LDBEN 9.394 completa 25 anos. Ao ser instituída a então nova LDBEN em 1996, a arte tornou-se um componente curricular obrigatório na educação básica brasileira depois de anos de muitas lutas. Conseguimos avançar enquanto área de conhecimento, de pesquisa e de formação com o aumento de instituições e de cursos de graduação e pós-graduação. Nos últimos anos, porém, enfrentamos um retrocesso da mesma intensidade como o que ocorre na educação, em geral, e na democracia do Brasil e de outros países da América Latina.

Com esse cenário, os argumentos de manutenção e avanço da arte, da educação e da formação no país parecem ter sido subtraídos de sentido. E, igualmente, temos a sensação de estar diante dos limites das nuances conceituais mais ativas entre arte e educação: arte e educação, arte na educação, arte na escola, ensino da arte, ensino em arte, arte-educação, arte/educação, arte e docência, arte na docência. Reconhecemos essas diferentes feições, porém o 


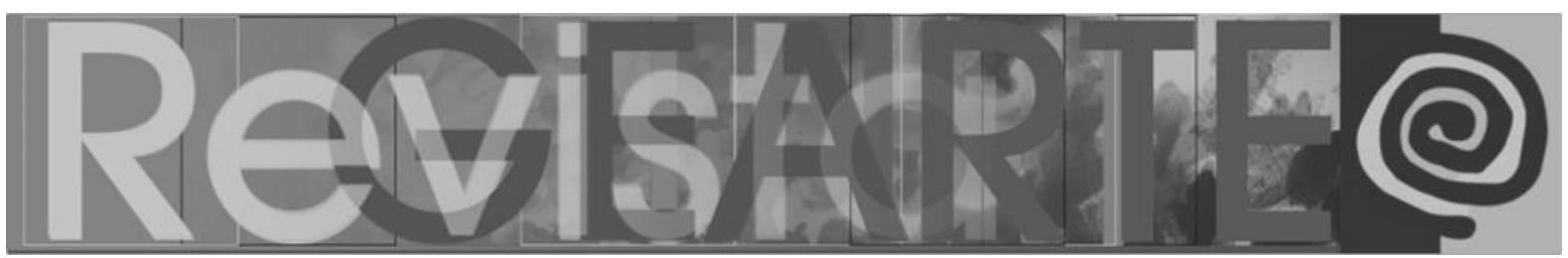

momento de ebulição política e o desmonte das instituições também sugerem que façamos atualizações no acervo conceitual que estabelecemos e na sua capacidade de comunicação com todos os setores com os quais se relaciona.

A desestruturação da organização educacional brasileira se articula com o momento atual. Estamos atravessando o segundo ano da pandemia da COVID-19 e está exposta, em todos os níveis, a inépcia administrativa vigente, inseparável das reverberações do nosso percurso colonial. Baseado na exploração incessante da natureza, das culturas e das pessoas, especialmente as que são sistematicamente forçadas a permanecerem em menoridade social, vemos a exposição da ordem social autoritária e violenta do Brasil, fazendo, do nosso país, uma ameaça global.

No contexto mundial, Bruno Latour (2020) assinala a explosão das desigualdades, a ascensão de estados nacionais autoritários, a mutação do clima e a perda de uma orientação comum. Daí a necessidade de aterrar, pousar, traçar um mapa das posições políticas para observar e redefinir as bases, itens que trazemos do autor para focalizar em arte e educação.

Hoje, dos problemas que acometem a educação em artes, destacamos o caráter da Base Nacional Comum Curricular para a educação básica e o ensino remoto. O primeiro abre um conjunto de questões como: a diluição do conhecimento artístico na escola, a retirada de temas humanos pungentes dos documentos normativos, como gênero, a simplificação da educação básica pela ênfase restrita à formação para o trabalho sem abri-lo ao questionamento pelos jovens. Isso pode acentuar a construção de uma subjetividade individualista e produtivista, porque tonalizada pela lógica da aquisição (consumo) do conhecimento, da competição meritocrática e da auto-exploração em todas as áreas do conhecimento, inclusive na arte.

O momento de quebra e trauma social, então, produz um pouso forçado que reivindica a mobilização de uma capacidade de pensar significada por corpos e 


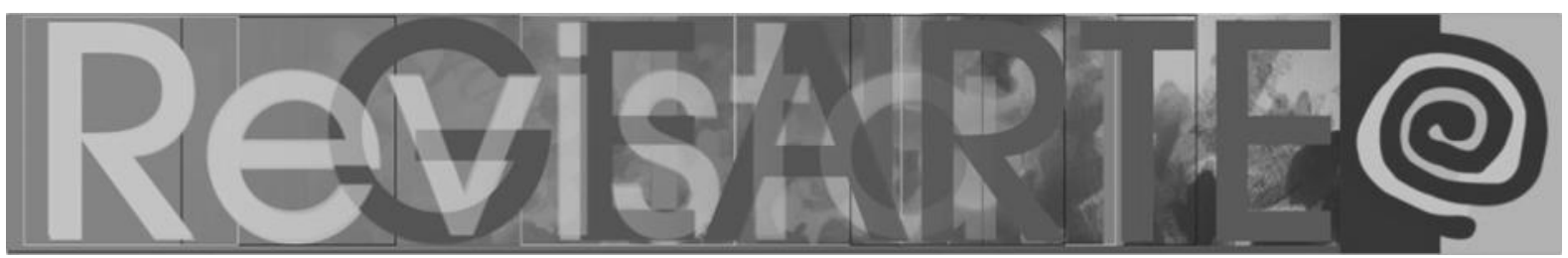

experiências inadiáveis. No momento em que estamos aterrados sob as mesmas restrições sanitárias e sociais, abriu-se uma oportunidade para observar o enlace entre educação e arte a partir de outros significados e direções. A proposição de Isabelle Stengers, mesmo que trate da filosofia da ciência, anima-nos a "[...] experimentar o poder de recriar - fazer pegar novamente, como se diz das plantas - a capacidade de pensar e agir juntos" (2015, p. 148).

A disposição dos textos que compõe este dossiê foi feita por aproximações como as ondas que se formam nas águas que, por vezes, tocam-se, cruzam-se e misturam-se. Tomamos o impulso dado pela pesquisa poética de Marcela Morado (2018) sobre a iconografia dos códices mexicanos para pensar e representar a água e, mais especialmente, quando a artista trabalha sobre as águas do Rio Guaíba, em Porto Alegre. As ondas sugeridas para o dossiê (Figura 1) trazem as palavras-chave dos artigos, sugerindo movimentos entre elas.

Propomos três ondas: posturas (in)concebíveis, práticas vivas e perturbar monoculturas. Ao mesmo tempo, cada pessoa, ao adentrar neste Dossiê, poderá fazer as suas próprias aproximações a partir dos interesses que a impulsionam a mergulhar em cada texto.

Posturas (in)concebíveis faz referência ao fazer educativo, às insurgências diárias que mobilizam posturas que movimentam os saberes da arte e da educação pela atuação de docentes pesquisadoras e pesquisadores, ainda que produzidas no interior de campos de conhecimento determinados. Aí, aproximam-se os textos escritos por Gustavo Torrezan (Centro de Pesquisa e Formação do Sesc), Habitar o dissenso, germinar alegria, e por Sumaya Matar (Universidade de São Paulo, Brasil), Ensino de arte e formação de professores: a aula como invenção de possibilidades. A autora e o autor fazem uma imersão no espaço educativo a partir da experiência artística e da inteligência criadora. Instigam-nos a pensar sobre a experiência de existir como artistas em espaços como a escola e a universidade, mas sobretudo na descoberta de estar docente. 


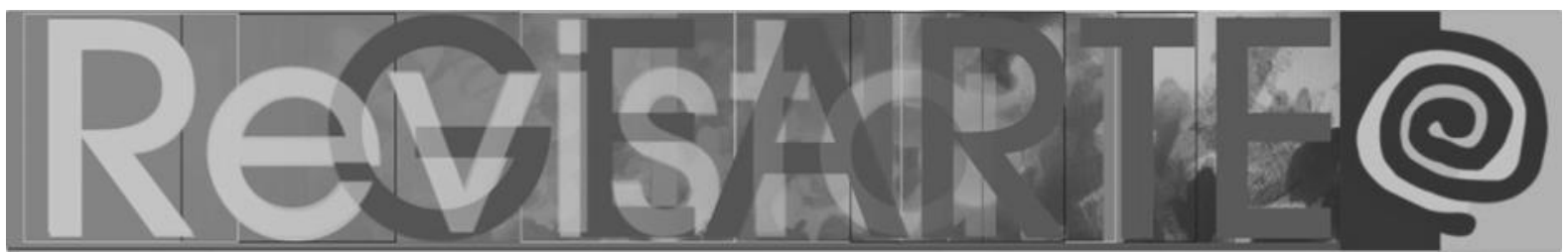

Figura 1 - Diagrama - ondas. Autoria: Carmen Lúcia Capra, 2021

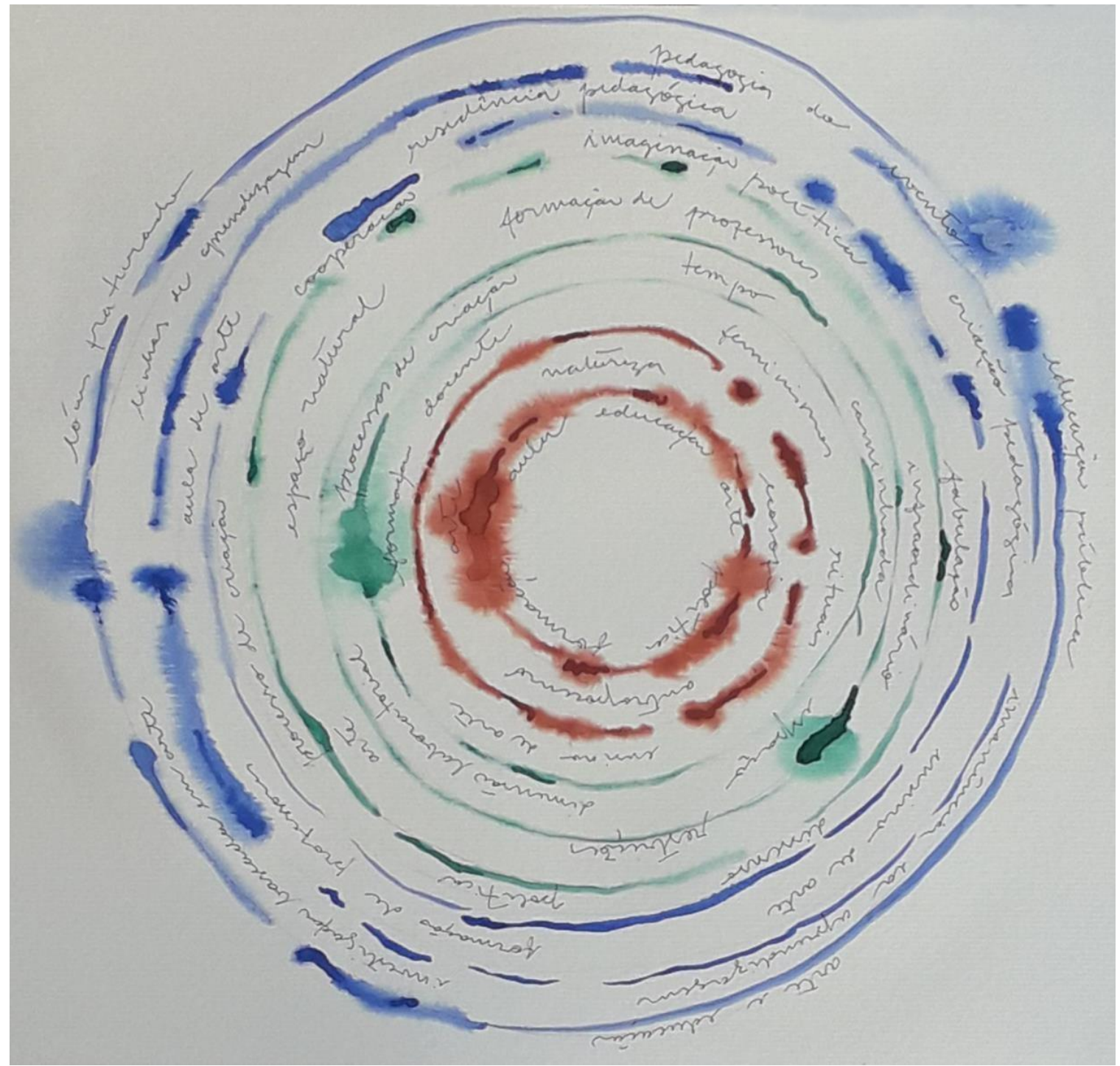

Fonte: Acervo dos Autores (2021).

Práticas vivas trata de uma imersão que nos sugere pensar na própria condição de ser/pensar/estar docente como em uma procura sobre si mesmo na relação com outro e o mundo. O texto de Tatiana Fernandez (Universidade de Brasília, Brasil), De linhas e marcas de existência: o evento pedagógico como evento artístico, convoca uma experiência que se movimenta em múltiplas direções quando pensamos a aula, as práticas, os processos educativos/formativos com arte e educação. 


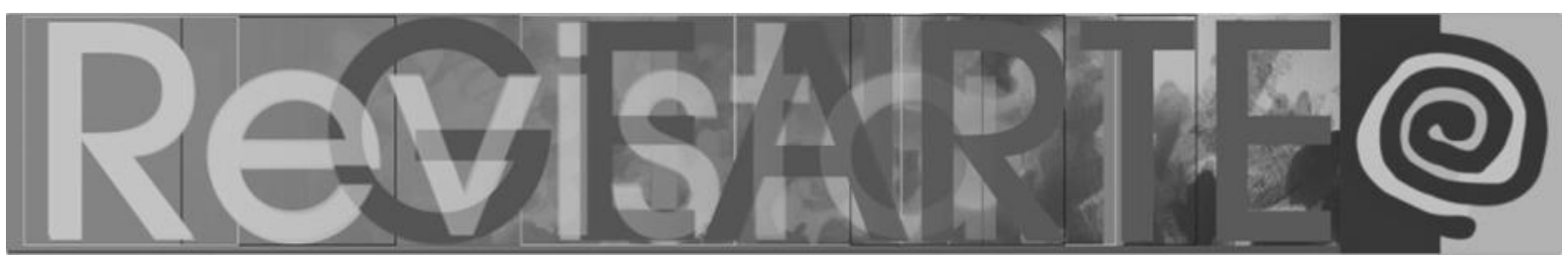

Perturbar monoculturas provoca uma imersão no contexto universitário e impulsiona a buscar práticas que escapam do viés universalista e simplificador que pode vir a limitar ou sobrepor-se aos territórios criados pela confluência entre arte e educação. Dessa maneira, aproximam-se os textos de Silvia Marques (Universidade Federal do Amapá, Brasil) em Do lado de cá da linha do equador: tentavias do pensar/saber/sentir a existência docente em artes visuais, de Rocío Arregui-Pradas (Universidade de Sevilla, Espanha) em De la morfología de la naturaleza a la ecosofía: experiencia didáctica en máster en arte e de Gloria Jové (Universidade de Lleida, Espanha) em Pupitres a la intemperie: ¿cómo las restricciones en el contexto pandémico han condicionado el proceso de creación en la formación docente?. Os textos nos convidam a pensar a formação e a existência docente em arte por meio das formas de habitar a universidade.

Ficará a cargo de quem acessar o dossiê observar os movimentos que propusemos ou encontrar outras ondas e intensidades.

Ao final desta apresentação, deixamos nosso agradecimento às autoras e autores em formarem uma comunidade docente, mesmo que atravessando dificuldades sanitárias, laborais, econômicas e psicológicas. Estendemos o reconhecimento as outras convidadas e convidados que, pela intensidade das dificuldades citadas, foram impedidos de concluir o percurso. A disposição para narrar, escutar e estar em conversação com outras/os docentes e pesquisadoras(es) é um elogio ao ato inconformado do pensamento sobre a aula e sobre os processos formativos/educativos. Em um momento de irremediáveis impactos culturais, sociais, políticos e ambientais, voltar-se à escuta do que ainda pode ser dito e comunicar-se são duas ações que armam uma posição "outra" (GROS, 2011) sobre a nossa experiência política com os saberes da arte e da educação. 


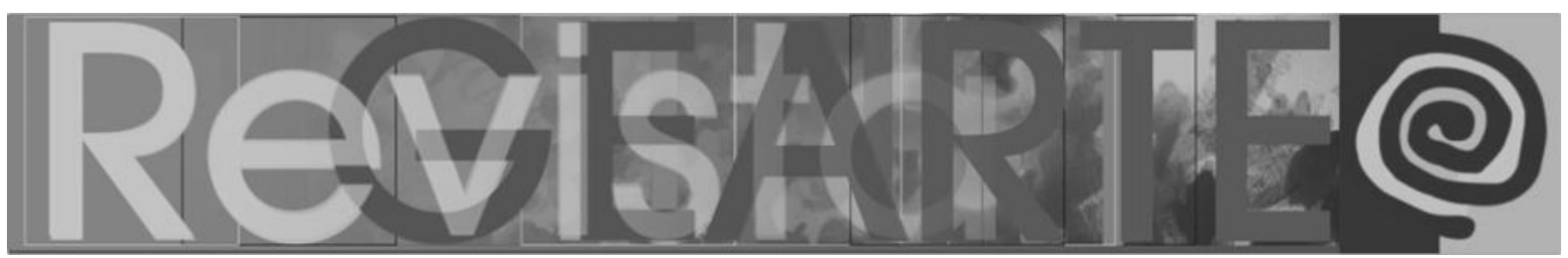

\section{Nota}

1 Como pano de fundo estão Isabelle Stengers (2015) e Reinaldo Laddaga (2012). Este, explica como a cultura epistêmica baseada em uma oposição naturaliza as investigações no campo da biologia e da arte (vida - não vida; arte - não arte). E Stengers alerta para a diferença entre as articulações em torno de uma causa comum e, bem diferente, tomar o poder em prol exatamente da causa comum.

\section{Referências}

BAHENA, Martha Marcela Morado. Cinco agua: en la casa de los cinco ríos. Uma poética das representações da água. Porto Alegre: Universidade Federal do Rio Grande do Sul. 2018. 168f. Tese de Doutorado. Programa de Pós-Graduação em Artes Visuais da Universidade Federal do Rio Grande do Sul. 2018.

FOUCAULT, Michel.Em defesa da sociedade: curso no Collége de France. 2 ed. Martins Fontes: São Paulo, 2010.

GROS,Frédéric.Situação do curso. In: FOUCAULT, Michel. A coragem da verdade: o governo de si e dos outros II: curso no collège de France (1983-1984). Martins Fontes: São Paulo, 2011. p.301316 IAMARINO, Atila. Live 31/03/21 - Ainda vai demorar. Disponível em: https://www.youtube. com/watch?v=2DTjWQXFbho Acesso em 2 abr. 2021.

LADDAGA, Reinaldo. Estética da Emergência. São Paulo: Martins Fontes, 2012.

LATOUR, Bruno. Onde aterrar? Como se orientar politicamente no antropoceno. Rio de Janeiro: Bazar do Tempo, 2020.

RANCIÈRE, Jacques. Partilha do Sensível. Estética e Política. Tradução de Mônica Costa Netto. São Paulo: EXO experimental org.; Ed..34, 2005.

STENGERS, Isabelle. No Tempo das Catástrofes - resistir à barbárie que se aproxima. São Paulo: Cosac Naify, 2015.

Profa. Dra. Carmen Lúcia Capra ${ }^{1}$ (Universidade Estadual do Rio Grande do Sul — UERGS, Montenegro/RS, Brasil)

Prof. Dr. Daniel Bruno Momoli² (Universidade Estadual do Paraná — UNESPAR, Curitiba/PR, Brasil)

Profa. Dra. Silvia Carla Marques ${ }^{3}$ (Universidade Federal do Amapá — UFAP, Macapá/AP, Brasil)

Organizadores do presente número

1 Licenciada em Educação Artística pela Universidade de Caxias do Sul (UCS), mestra e doutora em Educação pela Universidade Federal do Rio Grande do Sul (UFRGS). Atualmente é professora da Universidade Estadual do Rio Grande do Sul (Uergs) na Graduação em Artes Visuais e no Mestrado Profissional em Educação. Lidera o Grupo de Pesquisa Flume Educação e Artes Visuais (Uergs/CNPq) e se dedica à pesquisa sobre a formação docente em artes visuais com foco na atuação em escola. Integra o Núcleo Educativo MARGS-Uergs e participa do Grupo

CAPRA, Carmen Lúcia; MOMOLI, Daniel Bruno; MARQUES, Silvia Carla. Proposições educativas 647

e formativas em arte: do (im)previsível dessas composições aos arranjos e invenções de uma aula.

Revista GEARTE, Porto Alegre, v. 8, n. 3, p. 639-648, set./dez. 2021.

Disponível em: http://seer.ufrgs.br/gearte 


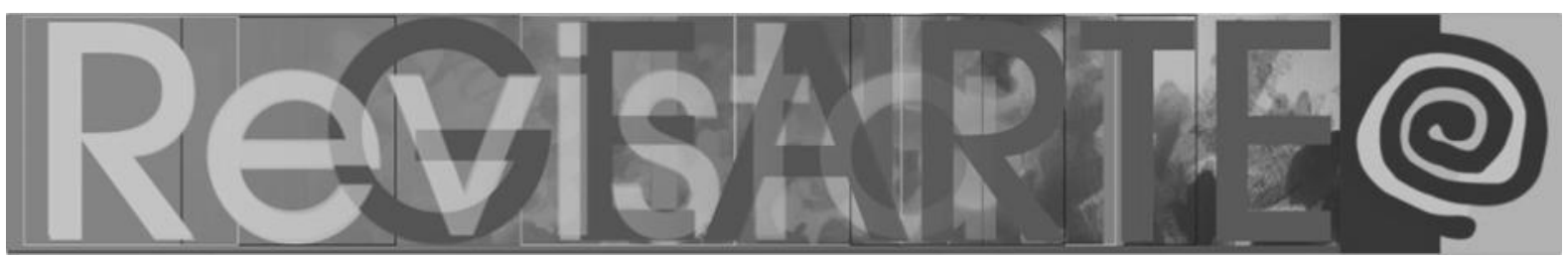

de Pesquisa Arteversa (UFRGS/CNPq). Tem atuado na promoção de ações de cunho artístico e educativo que permitam conversações entre ensino, pesquisa e extensão, a exemplo do Projeto Vincular (Núcleo Educativo MARGS - Uergs, Porto Alegre/RS), Exposição e Seminário Salas (Montenegro, RS), Dia do Desenho (Montenegro, RS), Bordado Livre na Praça (Montenegro/RS), participando de grupos experimentais de curadoria e prática artística.

2 Doutor e Mestre em Educação pela Universidade Federal do Rio Grande do Sul, Especialista em Educação Interdisciplinar pelo Instituto de Desenvolvimento do Alto Uruguai, Licenciado em Artes pela Universidade do Oeste de Santa Catarina. Foi Vice-presidente da Federação de Arte Educadores do Brasil-FAEB (2019-2020). É pesquisador vinculado ao Arteversa-Grupo de estudos e pesquisas em arte e docência (UFRGS/CNPq), Flume-Educação e Artes Visuais (UERGS/CNPq), GAEFO-Grupo de Pesquisa em Arte, Educação e Formação Docente (UNESPAR/CNPq). É professor da Universidade Estadual do Paraná, no campus Curitiba II atuando na licenciatura em artes visuais. Foi um dos articuladores das Jornadas em Defesa da Educação Democrática e do Pensamento de Paulo Freire e do Movimento Popular-Pedagógico Escola do Povo ações político-pedagógicas criadas em 2019 junto com os movimentos sociais, movimentos em defesa da educação, trabalhadoras(es) em educação.

3 Doutora em Sociologia. Mestre em Arte e Cultura Visual; Especialista em Instituições Culturais. Professora da Universidade Federal do Amapá. Tem interesse por questões da visualidade e processos de aprendizagem na formação inicial e continuada de professores em artes visuais. Abordagem acerca das relações estéticas nos mundos da arte e poéticas nos processos culturais nas cidades. Atua principalmente nos seguintes temas: Processos educativos em Arte, Poéticas Sociais, Feminismo, estéticas urbanas e cotidiano. 